\title{
Proximity Bias Following Affective Metaphors in Patients With Depression-Psychoanalytic Considerations
}

\author{
Iftah Biran ${ }^{1,2,3 \star}$, Assaf Tripto ${ }^{1,4,5}$ and Anat Arbel ${ }^{1,4}$ \\ ${ }^{1}$ Division of Psychiatry, Chaim Sheba Medical Center, Ramat Gan, Israel, ${ }^{2}$ Neurological Institute, Tel Aviv Sourasky Medical \\ Center, Tel Aviv, Israel, ${ }^{3}$ The Israeli Neuropsychoanalysis Society, Kadima, Israel, ${ }^{4}$ Sackler Faculty of Medicine, Tel Aviv \\ University, Tel Aviv, Israel, ${ }^{5}$ Beeri Clinic, Kupat Holim Clalit, Bnei Brak, Israel
}

\section{OPEN ACCESS}

Edited by: Andrea Clarici,

University of Trieste, Italy

Reviewed by:

Daniele Paradiso,

University of Turin, Italy

Daniela Flores Mosri, Universidad Intercontinental,

Mexico

*Correspondence: Iftah Biran

i_biran@hotmail.com

Specialty section: This article was submitted to

Psychoanalysis and Neuropsychoanalysis, a section of the journal

Frontiers in Psychology

Received: 05 August 2019 Accepted: 14 October 2019 Published: 06 November 2019

Citation:

Biran I, Tripto A and Arbel A (2019) Proximity Bias Following Affective

Metaphors in Patients With Depression-Psychoanalytic Considerations.

Front. Psychol. 10:2438. doi: 10.3389/fpsyg.2019.02438
Background: Many languages use spatial metaphors to describe affective states such as an upward bias to denote positive mood, a downward bias to denote negative mood, a body proximity bias to denote personal relatedness concern, and a right-left bias to denote negative or positive valence. These biases might be related to experiential traces related to these affective states. If this is the case, depressed subjects would show either a downward spatial bias, a body proximity bias, or a right-left shift in attention. We evaluated the occurrence of such biases in subjects with depression compared to healthy controls. Methods: Subjects: 10 subjects with depression (5F:5M; age $=47.2 \pm 15.2$ ) and 10 healthy controls (5F:5M; age $=45.8 \pm 14.5)$. Experimental task: line bisection task. Lines were presented in three spatial orientations [vertical (up-down), horizontal (right-left), radial (proximal-distal)] and were either blank, composed with words (negative/positive/neutral), or with smileys (negative/positive/neutral). There were 21 line types, and each was presented eight times, reaching a total of 168 lines.

Results: Compared with healthy controls, subjects with depression bisected radial lines significantly closer to their body. There were no significant differences for either horizontal or vertical lines.

Conclusion: The proximity spatial bias observed in subjects with depression suggests that depression might activate neural spatial networks. We argue that these networks could be dynamically activated through narcissistic mechanisms as implied in "Mourning and Melancholia" where Freud postulates a narcissistic mediated bias in depression according to which the depressed subjects withdraw from the outside world.

Keywords: depression, metaphors, embodiment, line bisection, spatial attention

\section{INTRODUCTION}

Many languages convey emotional states through spatial metaphors, such as the spatial "updown" metaphor where "down" denotes sad or depressed mood, whereas "up" denotes good mood to the extent of manic states.

These spatial metaphors are common in our daily use (Lakoff and Johnson, 2003b): In the negatively charged downward direction: "depressed mood," "feeling down," "he is really low," "he 
fell into depression," and "my spirits sank,", and in the opposite direction: "elevated mood," "feeling high," "that boosted my spirits," and "my spirits rose," Similar metaphors are found across different cultures and multiple languages [e.g., in German - "in Stimmungstief sein" (to be in a depressed mood), "in gehobener Stimmung sein" (to be in high spirits); in French - "une baisse d'humeur" (low mood), "montée de l'humeur" (increase in the mood); and in Hebrew - "matzav ruach meromam" (elevated mood), "matzav ruach yarud” (depressed mood)].

This metaphoric vertical spatial encoding of affective states is also encountered in literature and poetry. Emily Dickinson brings in her poem "I felt a Funeral, in my Brain", a horrifying description of depression illustrated as a never ending fall "And then a Plank in Reason, broke,/And I dropped down, and down - /And hit a World, at every plunge,/And Finished knowing - then -"(Dickinson, 1983). This depressive downward fall fits the common western metaphors of depression as falling down and descent (Pritzker, 2003; McMullen and Conway, 2014).

Spatial affective metaphors are not limited to the vertical up-down axis and can be extended to a horizontal right-left axis where right is regarded as good and left is regarded as bad (Drago et al., 2010) or to a horizontal toward-away/distal-proximal (radial) axis - as in "it touched my heart," "it touched me," and "I am going to leave it behind my back", all of which are used to denote an affective personally loaded state and can shed light on the individual's personality style (Hastings, 1952; Fisher, 1964).

Are these "real" metaphors in the sense that they entail symbolic idiomatic thinking or are they mere concrete embodiment of the affective state?

In order to address this, we first have to look at the definition of metaphors. Classically, metaphors are regarded as a figurative act of speech in which a "thing" from one domain is used to describe a second "thing" from a different domain or as "the cognitive mechanism whereby one experiential domain is partially 'mapped, i.e., projected, onto a different experiential domain, so that the second domain is partially understood in terms of the first one" (Barcelona, 2000). The definition of metaphors in the Merriam-Webster dictionary is similar: "a word or phrase denoting one kind of object or action is used in place of another to suggest a likeness or analogy between them." In this regard, a metaphor is a tool used to suggest or direct the addressee to a rather obscure and hidden similarity between two entities from different domains, and in order to understand the metaphor, one should find out what is depicted by the metaphor and what quality is transposed between the two domains.

Lakoff and Johnson in their book "Metaphors We Live By" use a definition that at first hand seems similar to the abovequoted classic definitions but is quite different and signifies a revolution in the study of metaphors their definition goes as follows: "The essence of metaphors is understanding and experiencing one kind of thing in terms of another" (Lakoff and Johnson, 2003a, p. 5). This combination of both understanding and experiencing suggests that a metaphor is both a cognitive entity and a symbolic entity and that it stems from both

${ }^{1}$ https://www.merriam-webster.com/dictionary/metaphor; Downloaded - 5/8/2019. understanding through a cognitively mediated process as well as from an experiential act that is felt directly as the thing itself.

Going back to spatial affective metaphors: The question whether affective metaphors are a figure of speech mediated by linguistic cognition or an experiential phenomenon is related to a clinical issue - that of symbolization charged with unconscious meaning as opposed to (or differing from) concrete thinking and experiences. When a patient uses affective metaphors in an encounter with his or her therapist, can these be reduced (or expanded) to a covert underlying meaning that is exposed through analytic work? Or rather that these spatial metaphors express bodily sensations and are the experience itself? This carries within clinical implications as the former directs to classic psychoanalytic work emphasizing on the verbal while the latter directs to bodily based techniques emphasizing on the non-verbal and on embodied attentiveness (Bloom, 2000, 2018).

If affective spatial metaphors are indeed experiential, we can expect a spatial bias in affective loaded conditions. This is in accordance with the Hebbian postulate that "Neurons that fire together wire together" (Hebb, 1949) ${ }^{2}$, and in this context, affective networks that co-activate with certain body-spatial networks synapse together.

Previous research demonstrated this spatial-affective interaction mainly in healthy non-depressed subjects. Most of the studies looked at just one axis (either vertical, horizontal, or radial) and did not address the various axes using a single paradigm.

Drago et al. demonstrated that subjects tended to place a mark on a blank sheet of paper according to an affective state induced experimentally. On a radial-vertical axis (going from higher-distal to lower-proximal), healthy subjects marked the page more distally and higher following happy conditions and more proximal and lower following sad conditions (Drago et al., 2010). Foster et al. demonstrated using a similar paradigm that healthy subjects placed pegs labeled with various emotions differentially on a board. Positively labeled pegs were placed higher and distally (Foster et al., 2008). In another study, exposure to happy music activated a rightward bias in visuospatial horizontal line bisection, whereas exposure to sad music activated an opposite bias (Barrow, 2013). Fisher demonstrated that healthy subjects in a sad mood, as judged by the way they described faces, tended to have a preference for downward movements and while adjusting rods in a horizontal position tended to err downward (Fisher, 1964).

Surprisingly, although there is an extensive research regarding general non-directional spatial attentional impairments in depressed subjects [see, e.g., the study by Ossowski et al. (2011)], there is almost no research regarding specific directional spatial bias in depressed population. Using tachistoscopic presentation of happy-sad chimeric face drawings, David et al. were able to show that while healthy controls and manic patients tend to have a leftward attentional bias (they tend to perceive the left hemi-face), depressed patients do not show this effect (David, 1993). Studies looking

${ }^{2}$ The original quote from Hebb goes as follows: "When an axon of cell A is near enough to excite a cell B and repeatedly or persistently takes part in firing it, some growth process or metabolic change takes place in one or both cells such that A's efficiency, as one of the cells firing B, is increased" (Hebb, 1949, p. 62). 
at the performance of depressed subjects bisecting horizontal lines presented on the right-left axis were inconclusive (Cavezian et al., 2007; Ramos-Brieva et al., 2009; Wei et al., 2010). To the best of our knowledge, there are no studies that looked at the vertical or the radial axes in subjects with depression.

The notion that spatial affective language is at times not figurative, but rather concrete is supported not only by experimental studies but also by observations on healthy subjects, clinical observations, and observations in psychodynamic therapy.

Canales et al. showed that depressed patients, in accordance with a downward bias, show a kyphotic flexed position of their trunk and that this position is normalized upon recovery (Canales et al., 2010). Similarly, subjects with symptoms of depression tend to be in an inclined protruded posture (Rosario et al., 2014). Reading sentences with themes of depression facilitated downward movement of healthy subjects (Santana and de Vega, 2011).

This can also be encountered in images, dreams, and associations brought to therapy by depressed patients (McMullen and Conway, 2014). Here are illustrative clinical examples: (1) an elderly man presenting with psychotic depression who describes how he is buried alive down under a tombstone, sand, and earth. The spatial distortion evident in this example is a vertical downward bias. (2) A young woman with depressive disorder and defensive grandiose defenses brings a dream in which she is transported from a cave like crypta of an underground city toward a highrise. This journey is facilitated through a travel in a cable car that travels both in a horizontal forward direction and a vertical upward direction. This dream that was interpreted as a flight from her depression brings together both the vertical and the horizontal - radial axes. (3) Horizontal right-left bias could be the source for the higher prevalence of left sided hemiplegic conversion suggesting negative connotations and valence attributed to the left side. However, this finding is questionable and could be related to reporting bias (Stone et al., 2002).

Previous research and clinical observations did not compare the relative deviations of (or impairments to) the different axes. However, psychodynamic formulations are in accordance with the significance of an operation on the radial axis as an emblem of an inside-outside gradient. Such is the narcissistic formulation of depression as conceptualized by Freud. Freud suggests that depression is an inward withdrawal from the outside world to the inner world, accompanied by decathexis of real-world objects (Freud, 1917[1915]).

Do the above formulation as well as the spatial metaphors of depression have embodied correlates? In this study, we compare the spatial bias of depressed patients with that of healthy controls across all three axes [vertical (up-down), horizontal (right-left), radial (proximal-distal)]. We adapted the line bisection task that is usually used to test horizontal (right-left) spatial bias in patients with neglect following right hemispheric injury. These patients tend to neglect the left side of the space and to bisect horizontal lines in a position that is located right to the midline (Schenkenberg et al., 1980). As the same stimuli (lines) could be presented in different orientations while keeping the same visual characteristics, this task could be used to compare performance across all axes.
We hypothesize that subjects with depression would show a specific spatial bias in each of the axes - a leftward deviation in bisecting horizontal lines, a downward deviation in bisecting vertical lines, and a proximal deviation bisecting radial lines. We further hypothesized, based on the dynamic formulations of narcissistic bias in depression, that the deviation would be more prominent in the radial condition.

\section{METHODS}

\section{Subjects}

Depression group (DEP): 10 adult subjects with depression were recruited from the outpatient psychiatric clinic of the Chaim Sheba Medical Center at Tel Hashomer. Depression diagnosis was based on clinical interview by a certified psychiatrist, and they all met DSM-5 criteria for depression (American Psychiatric Association, 2013). Patients were treated with either anti-depressants, individual psychotherapy, group psychotherapy, or a combination. Control group (CON): 10 sex- and age-matched control subjects were recruited by the research team using snowball sampling and direct recruitment.

\section{Ethics}

The study was approved by the Institutional Review Board (Helsinki Committee) of the Chaim Sheba Medical Center at Tel Hashomer.

\section{Baseline Characteristics}

Cognitive functions were evaluated by The Neurobehavioral Cognitive Status Examination Revised 2011 (Cognistat) that enables the assessment of various cognitive domains (Kiernan et al., 1987; Katz et al., 1996; Cognistat, 2011). Depression was evaluated by filling out the Beck Depression Inventory-II (BDI-II) (Gil and Gilbar, 2001; Steer and Beck, 2001).

\section{Experimental Task}

The experimental task was based on the line bisection task that is used to assess hemi-spatial neglect. In this task, the subject is asked to bisect a line in its midline (Schenkenberg et al., 1980). A deviation from the midline suggests an attentional bias. Lines were administered in three axes: vertical (up-down), horizontal (right-left), and radial (proximal-distal) (see Figure 1). Lines were $10 \mathrm{~cm}$ long and $0.5 \mathrm{~cm}$ wide. There were seven line types: a blank line; three line types with word cues at their ends: happy, sad, and neutral words; and three line types with visual affective cues at their ends: happy, sad,

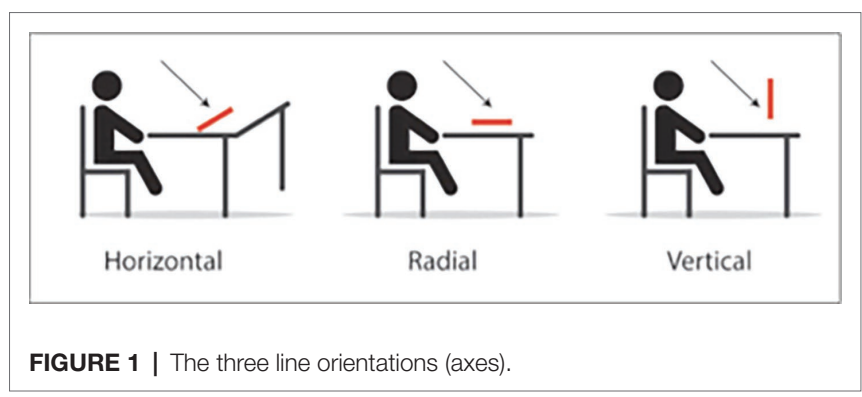




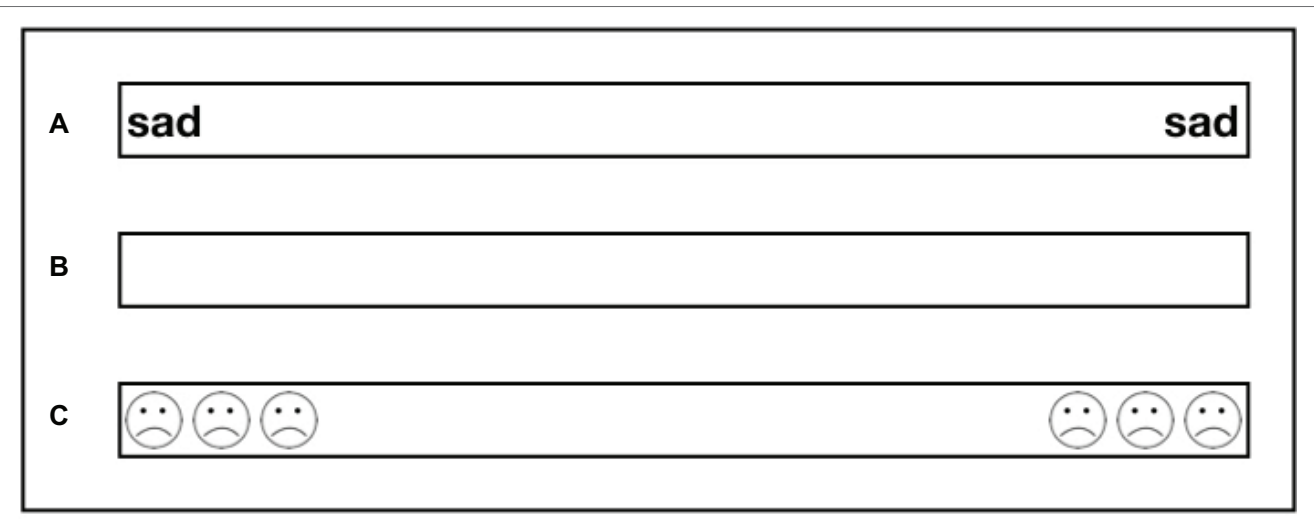

FIGURE 2 | Illustration of the various line types. (A) Horizontal negative word line; (B) Horizontal blank line; (C) Horizontal negative smiley line.

and neutral smileys (see Figure 2 for an example of the different line types). Each line type was presented eight times in each axis. In total, each subject was asked to bisect 168 lines [21 conditions ( 3 axes $\times 7$ line types) $\times 8$ repetitions for each condition]. Following the method used by Schenkenberg et al. (1980), all 8 repetitions of each of the 21 conditions were printed on an A4 paper with a distance of $1.8 \mathrm{~cm}$ between each line and were presented randomly at a distance of $30 \mathrm{~cm}$ from the subjects. The measurements were done using ABSOLUTE Digimatic Caliper with an accuracy of $0.001 \mathrm{~cm}$ (Mitutoyo, 2016). The point of bisection was measured twice for each line, and the two measurements were averaged. The measurements were as follows: the distance from the left for horizontal lines, the distance from the top for vertical lines, and the distance from the distal end for the radial lines.

\section{Statistical Analysis}

Data were entered and analyzed using SPSS version 24. Descriptive statistics were produced using means and standard deviations for continuous variables (e.g., age), and frequencies for categorical variables (e.g., sex). To examine differences between groups in continuous variables, $t$-tests were conducted. To examine differences between groups in categorical variables, Chi-Square tests were conducted. Variables were tested for normal distribution using Kolmogorov-Smirnov procedures. To test study hypotheses, multivariate analysis of covariance (MANCOVA) was conducted. The level of significance is $5 \%$.

\section{RESULTS}

\section{Baseline Characteristics}

Participants in both groups were matched for gender, age, and education, and there was no significant difference between the two groups across these variables (see Table $\mathbf{1}$ ).

As expected, average BDI-II was significantly higher among participants who were diagnosed with depression in comparison with the control group $(25.10 \pm 5.64$ vs. $3.1 \pm 2.07$, respectively, $p<0.001$ ) (see Table 1 ).

Comparison of the various cognitive domains between groups indicated no significant differences between groups across all cognitive domains (see Table 1).
TABLE 1 | Demographic and baseline characteristics.

\begin{tabular}{|c|c|c|c|}
\hline & Control & Depression & $\begin{array}{c}\text { Difference } \\
\text { between groups }\end{array}$ \\
\hline \multicolumn{4}{|l|}{ Demographics } \\
\hline$N$ (male/female) & $10(5 / 5)$ & $10(5 / 5)$ & $\chi^{2}=1, p=1.00$ \\
\hline Age & $45.8 \pm 14.5$ & $47.2 \pm 15.3$ & $t=0.21, p=0.83$ \\
\hline Education [years] & $15.3(2.4)$ & $15.0(2.7)$ & $t=0.26, p=0.80$ \\
\hline \multicolumn{4}{|l|}{ Depression } \\
\hline BDI-II score & $3.1(2.1)$ & $25.1(5.64)$ & $t=11.56, p<0.001$ \\
\hline \multicolumn{4}{|c|}{ Cognistat domains (normal range) } \\
\hline Orientation (9-12) & $12.00(0.00)$ & $11.70(0.48)$ & $t=1.96, p=0.06$ \\
\hline Attention (6-8) & $7.80(0.42)$ & $7.70(0.67)$ & $t=0.397, p=0.69$ \\
\hline $\begin{array}{l}\text { Language - } \\
\text { comprehension (5-6) }\end{array}$ & $5.90(0.31)$ & $5.90(0.31)$ & $t=0.000, p=1.00$ \\
\hline $\begin{array}{l}\text { Language - repetition } \\
(10-12)\end{array}$ & $12.00(0.00)$ & $12.00(0.00)$ & $t=0.000, p=1.00$ \\
\hline $\begin{array}{l}\text { Language - naming } \\
(6-8)\end{array}$ & $7.50(0.70)$ & $6.50(1.58)$ & $t=1.82, p=0.08$ \\
\hline Building (4-6) & $5.90(0.31)$ & $5.10(1.37)$ & $t=1.799, p=0.08$ \\
\hline Memory (9-12) & $9.10(2.99)$ & $10.00(3.36)$ & $t=0.631, p=0.53$ \\
\hline Calculia (3-4) & $4.00(0.00)$ & $3.60(0.96)$ & $t=1.309, p=0.20$ \\
\hline Similarities (5-8) & $7.90(0.31)$ & $7.80(0.63)$ & $t=0.447, p=0.66$ \\
\hline Decision (4-6) & $6.00(0.00)$ & $5.60(1.26)$ & $t=1.000, p=0.343$ \\
\hline
\end{tabular}

The BDI-Il scores are as follows: 0-13, minimal depression; 14-19, mild depression; 20-28, moderate depression; 29-63, severe depression.

\section{Experimental Task}

Prior testing the main hypothesis, normality tests were conducted for all measures using Kolmogorov-Smirnov procedure. All measures were found with normal distribution ( $p$ of K-S > 0.60). Therefore, in order to test the differences between groups, MANCOVA was conducted.

Compared with healthy controls, subjects with depression bisected radial lines significantly closer to their body, suggesting a proximity spatial bias. This bias was consistently found for happy smiley lines $(0.18 \mathrm{~cm}$ proximal, $p=0.03)$, sad smiley lines $(0.21 \mathrm{~cm}$ proximal, $p=0.02)$, happy word lines $(0.17 \mathrm{~cm}$ proximal, $p=0.05)$, and sad word lines $(0.25 \mathrm{~cm}$ proximal, $p=0.02)$. There were no significant differences for either horizontal or vertical lines (see Table 2). 
TABLE 2 | Deviations in bisection of radial lines (measurements are the distance from the distal end in centimeters. The midline is $5 \mathrm{~cm}$, proximal deviation is more than $5 \mathrm{~cm}$, and distal deviation is less than $5 \mathrm{~cm}$ ).

\begin{tabular}{|c|c|c|c|c|}
\hline Line types & & Control & Depression & $\begin{array}{c}\text { Difference } \\
\text { between } \\
\text { groups }\end{array}$ \\
\hline \multirow[t]{3}{*}{ Smiley lines } & Happy & $4.72 \pm 0.17$ & $4.90 \pm 0.18$ & $\begin{array}{l}F=5.38 \\
p=0.03\end{array}$ \\
\hline & Sad & $4.71 \pm 0.13$ & $4.92 \pm 0.22$ & $\begin{array}{l}F=6.55 \\
p=0.02\end{array}$ \\
\hline & Neutral & $4.73 \pm 0.17$ & $4.88 \pm 0.17$ & $\begin{array}{l}F=3.69 \\
p=0.07\end{array}$ \\
\hline \multirow[t]{3}{*}{ Word lines } & Happy & $4.70 \pm 0.18$ & $4.87 \pm 0.19$ & $\begin{array}{l}F=4.33 \\
p=0.05\end{array}$ \\
\hline & Sad & $4.70 \pm 0.15$ & $4.95 \pm 0.27$ & $\begin{array}{l}F=6.26 \\
p=0.02\end{array}$ \\
\hline & Neutral & $4.77 \pm 0.16$ & $4.86 \pm 0.16$ & $\begin{array}{l}F=1.36 \\
p=0.25\end{array}$ \\
\hline Blank line & - & $4.76 \pm 0.17$ & $4.88 \pm 0.12$ & $\begin{array}{l}F=2.79 \\
p=0.11\end{array}$ \\
\hline
\end{tabular}

\section{DISCUSSION}

To conclude, in this study, we were able to show that subjects with depression compared with normal controls tend to bisect lines presented in the radial axis with a proximal bias. That is, they tend to bisect radial lines significantly closer to their body compared with normal controls. This was observed for affective lines (happy and sad smileys, happy and sad words). No effect was observed for both horizontal and vertical lines.

Although this spatial bias is relatively small (up to $0.25 \mathrm{~cm}$ ), it confirms our hypothesis regarding a proximity bias. The small effect size for the spatial bias is not surprising as similar miniscule effect sizes were observed previously (Wei et al., 2010). In any case, it could be secondary to the methodology employed in the study. The subjects were not asked to judge the valence and the emotionality of the stimuli, and therefore, this was addressed only implicitly. Other studies that looked at emotional stimuli explicitly demonstrated a bigger effect size (Drago et al., 2008; Foster et al., 2008).

As negative and positive stimuli can influence attention differentially (Baumeister et al., 2001; Yiend, 2010), it is surprising that the radial proximity bias was observed for both negative and positive words and smileys. This could be related to various parameters such as the arousal level of the stimuli or the depression as depression by itself can mask the differences between negative to positive stimuli (Beck, 1963, 1964).

The fact that the attentional bias documented in performing the line bisection tasks was confined to the radial axis is intriguing. As the tasks were similar across all axes, it is suggestive that this difference is related to specific and inherent mechanisms related to depression. This is in accordance with Churches et al. who demonstrated different cognitive mechanisms for vertical attention as opposed to horizontal attention (Churches et al., 2018).

Can the observed proximity bias be explained in psychoanalytic terms? Object relation theories, as originally formulated by Fairbairn, stress the importance of the infant's need to relate to others. As the infant's original objects, the mother and her breast, have distinct spatial coordinates, psychological processes such as differentiation and incorporation are intertwined with spatial operations (Fairbairn, 1941, 1963; Akhtar, 2009; Groarke et al., 2019). We argue that the proximity bias observed in depressed patients echoes this association between object relations and spatial coordinates. We further suggest that this bias follows (or mirrors) linguistic metaphors.

This is in accordance with Freud's model of depression as outlined in "Mourning and Melancholia" where he claims that the melancholic withdraws from the outside world - "The distinguishing mental features of melancholia are a profoundly painful dejection, cessation of interest in the outside world" and that this process is related to decathexis of libido from an object in the outside world - "But the free libido was not displaced on to another object; was withdrawn into the ego" (Freud, 1917[1915]). The withdrawal follows narcissistic logic in the sense that in narcissistic operations subjects withdraw libidinal interest from the outside world onto the self. Thus, it can help in conditions with impoverished ego as the decathected libido, now bound to the depleted ego, enriches the ego and the self (Freud, 1914). Overall, this can serve as a defense against adverse object relations. The narcissistic object relationship protects the capacity to love as it makes the love - object seems like the self (Britton, 2004).

An alternative psychoanalytic model that explains this narcissistic spatial bias and withdrawal is the cannibalistic model of depression formulated by Karl Abraham. According to this model, depressed subjects internalize aggressions that are directed toward the outside world. Abraham stresses the role of aggression in the generation of depression, whereas an aggressive instinct is transmuted into depressive affect. The ambivalence toward the loved object and the wish to incorporate it takes the form of a cannibalistic action. The guilt feelings of the depressed are a reaction to his own cannibalistic oral desires (Abraham, 2002; Van Schoonheten, 2015).

Irrespective of the nature of what is being incorporated, whether it is an object that carries within ambivalent cathexis as formulated by Freud or aggressive representations as formulated by Abrams, our results suggest that the psychic incorporation is correlated with body and space coordinates.

The argument that objects' relations are mapped spatially is supported, as stated above, by early developmental paradigms that base early object relations on achieving a spatial-bodily distinction between the baby and the world and others within the world. Such paradigms stress the early spatial interactions with the caregiver through a unique intermediate environment such as Rey's "marsupial space" or Winnicott's holding environment (Winnicott, 1960; Rey, 1988; McDougall, 1992; Allnutt, 2016).

Regardless of the specific psychoanalytic model, what is the neurophysiological basis of this depressive narcissistic withdrawal and of the decathexis of libido from an outside object to an internal representation? The right hemisphere could be a good candidate as it serves both the representations of the relationship between the self and objects and spatial cognition. Following right hemisphere damage, the distinction between self and objects is impaired and mature object relations are substituted by narcissistic relations, and this is 
accompanied by spatial distortions (Kaplan-Solms and Solms, 2002; Solms and Turnbull, 2002). It could be argued that a relative right hemispheric dysfunction (or dysregulation) in depression or right-left hemispheres misbalance is contributing to this clinical phenomenon (Bruder et al., 2017), and indeed, the right hemisphere is implicated in self-reflection, inward withdrawal, and introspection (Molnar-Szakacs et al., 2005; Hecht, 2010a,b). All these are commonly associated with depression (Höping et al., 2006).

Following all of the above and regarding the spatial-bodily metaphors in depression, we suggest that these metaphors are unique as they are not a mere transfer of meaning from one domain (affective) to another domain (space and body) but rather represent a distinct cognitive operation culminating in the observed spatial deviations. At times, as implied by Rene Magritte's "Treachery of images," "a pipe is just a pipe" and the signifier is the thing itself. However, it can still be understood through associations, experiencing, re-experiencing, and understanding.

To conclude, we suggest that this spatial proximity bias follows (or mirrors) linguistic metaphors. Based on psychodynamic formulations of depression, this proximity bias might be related to narcissistic mechanisms in depression, according to which depression is characterized by withdrawal from the outside world (Freud, 1917[1915]). Limitations of the current study are the small patient group and evaluation of the depression by psychiatric tools such as BDI-II depression questionnaire and the DSM-5 criteria without better psychoanalytic characterization. Although, there are no specific questionnaires used to characterize the narcissistic dimensions of depressed patients, the formulation of introjective depression versus anaclitic depression could be employed. According to this formulation, introjective depression has some narcissistic characteristic. Further research looking at this distinction is warranted (Blatt and Maroudas, 1992; McDougall, 1992; Blatt et al., 2001). Further research looking at the radial axis through other paradigms is warranted.

\section{REFERENCES}

Abraham, K. (2002). "Letter from Karl Abraham to Sigmund Freud, March 31, 1915" in The complete correspondence of Sigmund Freud and Karl Abraham 1907-1925 ed. E. Falzeder (London/New York: Karnac), 303-306.

Akhtar, S. (2009). "Object-relations theory" in Comprehensive dictionary of psychoanalysis (London: Karmac), 194.

Allnutt, L. (2016). Dimensionality, identity and security: finding a home through psychoanalysis. J. Child Psychother. 42, 18-29. doi: 10.1080/0075417X.2016.1140872

American Psychiatric Association (2013). DSM 5 diagnostic and statistical manual of mental disorders. Washington, DC: American Psychiatric Association.

Barcelona, A. (2000). "Introduction: the cognitive theory of metaphor and metonymy" in Metaphor and metonymy at the crossroads: A cognitive perspective. ed. A. Barcelona (Berlin: Mouton de Gruyter), 1-28.

Barrow, J. H. (2013). The influence of musically-induced emotion on biases in visual and auditory spatial attention. Fairfax, VA: Doctor of Psychology, George Mason University.

Baumeister, R. F., Bratslavsky, E., Finkenauer, C., and Vohs, K. D. (2001). Bad is stronger than good. Rev. Gen. Psychol. 5, 323-370. doi: 10.1037/1089-2680.5.4.323

Beck, A. T. (1963). Thinking and depression: I. idiosyncratic content and cognitive distortions. Arch. Gen. Psychiatry 9, 324-333. doi: 10.1001/ archpsyc.1963.01720160014002

\section{DATA AVAILABILITY STATEMENT}

The datasets generated for this study are available on request to the corresponding author.

\section{ETHICS STATEMENT}

The studies involving human participants were reviewed and approved by the Institutional Review Board (Helsinki Committee) of the Chaim Sheba Medical Center at Tel-Hashomer. The patients/participants provided their written informed consent to participate in this study.

\section{AUTHOR CONTRIBUTIONS}

All authors designed the study. AT and IB evaluated the patients. AA collected the data and organized the data set. IB analyzed the data. IB wrote the first draft of the manuscript. All authors contributed to manuscript revision, read, and approved the submitted version.

\section{ACKNOWLEDGMENTS}

This study has been made possible in part by the Arrow Project of the Chaim Sheba Medical Center thanks to a grant endowed to Anat Arbel during her medical studies. The authors would like to thank the members of the Israeli Society for Neuropsychoanalysis for their support and comments. Early versions of this work were presented in the Annual Conference of the Israeli Neurological Association held in 2015 and the 17th Congress of the International Neuropsychoanalysis Society held in 2016 and published in abstract form (Biran et al., 2015; Biran, 2016). The version herewith is much expanded.

Beck, A. T. (1964). Thinking and depression: II. Theory and therapy. Arch. Gen. Psychiatry 10, 561-571. doi: 10.1001/archpsyc.1964.01720240015003

Biran, I. (2016). Narcissistic spatial bias in depression. Neuro-psychoanalysis 18, 196-197. doi: 10.1080/15294145.2016.1232124

Biran, I., Tripto, A., and Freund, A. (2015). Spatial bias following affective metaphors in patients with depression. J. Israeli Neurol. Assoc. 87.

Blatt, S. J., and Maroudas, C. (1992). Convergences among psychoanalytic and cognitive-behavioral theories of depression. Psychoanal. Psychol. 9, 157-190. doi: $10.1037 / \mathrm{h} 0079351$

Blatt, S. J., Shahar, G., and Zuroff, D. C. (2001). Anaclitic (sociotropic) and introjective (autonomous) dimensions. Psychother. Theory Res. Pract. Train. 38, 449-454. doi: 10.1037/0033-3204.38.4.449

Bloom, K. (2000). Movement as a medium for psychophysical integration. Free. Assoc. 8, 151-169.

Bloom, K. (2018). The embodied self: Movement and psychoanalysis. London, UK, Oxon, UK, New York, NY: Routledge.

Britton, R. (2004). Narcissistic disorders in clinical practice. J. Anal. Psychol. 49, 477-490. doi: 10.1111/j.0021-8774.2004.00479.x

Bruder, G. E., Stewart, J. W., and Mcgrath, P. J. (2017). Right brain, left brain in depressive disorders: clinical and theoretical implications of behavioral, electrophysiological and neuroimaging findings. Neurosci. Biobehav. Rev. 78, 178-191. doi: 10.1016/j.neubiorev.2017.04.021 
Canales, J. Z., Cordás, T. A., Fiquer, J. T., Cavalcante, A. F., and Moreno, R. A. (2010). Posture and body image in individuals with major depressive disorder: a controlled study. Rev. Bras. Psiquiatr. 32, 375-380. doi: 10.1590/ S1516-44462010000400010

Cavezian, C., Danckert, J., Lerond, J., Dalery, J., D'amato, T., and Saoud, M. (2007). Visual-perceptual abilities in healthy controls, depressed patients, and schizophrenia patients. Brain Cogn. 64, 257-264. doi: 10.1016/j.bandc.2007.03.008

Churches, O., Loetscher, T., Thomas, N. A., and Nicholls, M. E. R. (2018). Perceptual biases in the horizontal and vertical dimensions are driven by separate cognitive mechanisms. Q. J. Exp. Psychol. 70, 444-460. doi: 10.1080/17470218.2015.1131841

Cognistat (2011). The neurobehavioral cognitive status examination revised 2011 [Hebrew]. Jerusalem: Psychtec.

David, A. S. (1993). Spatial and selective attention in the cerebral hemispheres in depression, mania, and schizophrenia. Brain Cogn. 23, 166-180. doi: 10.1006/brcg.1993.1053

Dickinson, E. (1983). "I felt a funeral, in my brain, (340)" in The poems of Emily Dickinson: Variorum edition ed. R. W. Franklin (Cambridge MA: Harvard University Press).

Drago, V., Finney, G. R., Foster, P. S., Amengual, A., Jeong, Y., Mizuno, T., et al. (2008). Spatial-attention and emotional evocation: line bisection performance and visual art emotional evocation. Brain Cogn. 66, 140-144. doi: 10.1016/j.bandc.2007.06.005

Drago, V., Heilman, K. M., and Foster, P. S. (2010). Feeling down: idiom or nature? J. Neuropsychiatry Clin. Neurosci. 22, 338-344. doi: 10.1176/jnp.2010.22.3.338

Fairbairn, W. R. D. (1941). A revised psychopathology of the psychoses and psychoneuroses. Int. J. Psychoanal. 22, 250-279.

Fairbairn, W. R. D. (1963). Synopsis of an object-relations theory of the personality. Int. J. Psychoanal. 44, 224-225.

Fisher, S. (1964). Depressive affect and perception of up-down. J. Psychiatr. Res. 2, 25-30. doi: 10.1016/0022-3956(64)90026-3

Foster, P. S., Drago, V., Webster, D. G., Harrison, D. W., Crucian, G. P., and Heilman, K. M. (2008). Emotional influences on spatial attention. Neuropsychology 22, 127-135. doi: 10.1037/0894-4105.22.1.127

Freud, S. (1914). "On narcissism: An introduction" in The Standard Edition of the Complete Psychological Works of Sigmund Freud, Volume XIV (1914-1916): On the History of the Psycho-Analytic Movement, Papers on Metapsychology and Other Works. 1957, 67-102.

Freud, S. (1917[1915]). "On narcissism: An introduction" in The Standard Edition of the Complete Psychological Works of Sigmund Freud, Volume XIV (1914-1916): On the History of the Psycho-Analytic Movement, Papers on Metapsychology and Other Works. 1957, 67-102.

Gil, S., and Gilbar, O. (2001). Hopelessness among cancer patients. J. Psychosoc. Oncol. 19, 21-33. doi: 10.1300/J077v19n01_02

Groarke, S., Tobias, L., Fainstein, A., and Papiasvili, E. (2019). "Object relations theories (ORT)" in IPA inter-regional encyclopedic dictionary of psychoanalysis. Available at: https:/www.ipa.world/ipa/En1/en/Encyclopedic_Dictionary/ English/Copyright.aspx

Hastings, P. K. (1952). A relationship between visual perception and level of personal security. J. Abnorm. Soc. Psychol. 47, 552-560. doi: 10.1037/h0060140

Hebb, D. O. (1949). The organization of behavior: A neurophysiological approach. New York, NY: John Willey \& Sons, Inc.

Hecht, D. (2010a). Depression and the hyperactive right-hemisphere. Neurosci. Res. 68, 77-87. doi: 10.1016/j.neures.2010.06.013

Hecht, D. (2010b). Schizophrenia, the sense of 'self'and the right cerebral hemisphere. Med. Hypotheses 74, 186-188. doi: 10.1016/j.mehy.2009.07.032

Höping, W., De Jong-Meyer, R., and Abrams, D. (2006). Excessive self-focused attention and defensiveness among psychiatric patients: a vicious cycle? Psychol. Rep. 98, 307-317. doi: 10.2466/pr0.98.2.307-317

Kaplan-Solms, K., and Solms, M. (2002). "Psychoanalytic observations on five cases of right perisylvian damage: failure of mourning" in Clinical studies in neuropsychoanalysis: Introduction to a depth neuropsychology. eds. K. Kaplan-Solms and M. Solms (New York, London: Karnac), 148-199.

Katz, N., Elazar, B., and Itzkovich, M. (1996). Validity of the neurobehavioral cognitive status examination (COGNISTAT) in assessing patients post CVA and healthy elderly in Israel. Isr. J. Occup. Ther. 3, 185-198.

Kiernan, R. J., Mueller, J., Langston, J. W., and Van Dyke, C. (1987). The neurobehavioral cognitive status examination: a brief but quantitative approach to cognitive assessment. Ann. Intern. Med. 107, 481-485. doi: 10.7326/ 0003-4819-107-4-481
Lakoff, G., and Johnson, M. (2003a). Metaphors we live by. Chicago \& London: The University of Chicago Press.

Lakoff, G., and Johnson, M. (2003b). “Orientational metaphors” in Metaphors We Live By (Chicago \& London: The University of Chicago Press), 14-21.

McDougall, J. (1992). "Psychic pain and the psychosoma" in Plea for a measure of abnormality. 1st Edn. ed. Burnner-Mazel (New York: International Universities Press, Inc.), 421-452.

McMullen, L. M., and Conway, J. B. (2014). "Conventional metaphors for depression" in The verbal communication of emotions: Interdisciplinary perspectives. ed. S. R. Fussell (London, UK and New York, NY: Routledge), $167-181$.

Mitutoyo (2016). Mitutoyo's general catalog NO. E2016. Japan: Kanagawa.

Molnar-Szakacs, I., Uddin, L. Q., and Iacoboni, M. (2005). Right-hemisphere motor facilitation by self-descriptive personality-trait words. Eur. J. Neurosci. 21, 2000-2006. doi: 10.1111/j.1460-9568.2005.04019.x

Ossowski, U., Malinen, S., and Helton, W. S. (2011). The effects of emotional stimuli on target detection: indirect and direct resource costs. Conscious. Cogn. 20, 1649-1658. doi: 10.1016/j.concog.2011.08.015

Pritzker, S. (2003). The role of metaphor in culture, consciousness, and medicine: a preliminary inquiry into the metaphors of depression in Chinese and Western medical and common languages. Clin. Acupunct. Orient. Med. 4, 11-28. doi: 10.1016/S1461-1449(02)00013-0

Ramos-Brieva, J. A., Olivan, J., Palomares, A., and Vela, A. (2009). Is there right hemisphere dysfunction in major depression? Int. J. Neurosci. 23, 103-109. doi: 10.3109/00207458408985351

Rey, H. (1988). "Schizoid phenomena in the borderline" in Melanie Klein today, volume 1: Mainly theory: Developments in theory and practice. ed. E. B. Spillius (London, UK: Routledge), 197-223.

Rosario, J. L., Bezerra Diogenes, M. S., Mattei, R., and Leite, J. R. (2014). Differences and similarities in postural alterations caused by sadness and depression. J. Bodyw. Mov. Ther. 18, 540-544. doi: 10.1016/j.jbmt.2013.12.010

Santana, E., and De Vega, M. (2011). Metaphors are embodied, and so are their literal counterparts. Front. Psychol. 2:90. doi: 10.3389/fpsyg.2011.00090

Schenkenberg, T., Bradford, D. C., and Ajax, E. T. (1980). Line bisection and unilateral visual neglect in patients with neurologic impairment. Neurology 30, 509-517. doi: 10.1212/WNL.30.5.509

Solms, M., and Turnbull, O. (2002). "Words and things: the left and right cerebral hemispheres" in The brain and the inner world: An introduction to the neuroscience of subjective experience (London, UK: Karnac Books), 239-272.

Steer, R. A., and Beck, A. T. (2001). "Beck depression inventory II" in The Corsini encyclopedia of psychology and behavioral science. 3rd Edn. eds. I. B. Weiner and W. E. Craighead (New York, NY: John Wiley and Sons, Inc.), 178-179.

Stone, J., Sharpe, M., Carson, A., Lewis, S., Thomas, B., Goldbeck, R., et al. (2002). Are functional motor and sensory symptoms really more frequent on the left? A systematic review. J. Neurol. Neurosurg. Psychiatry 73, 578581. doi: 10.1136/jnnp.73.5.578

Van Schoonheten, A. B. (2015). Creation of a theory about early childhood and ejaculatio praecox. London and New York: Routledge.

Wei, H., Hao, C., Yingchun Zhang, S. Y., Wei, C., and Wei, W. (2010). Line bisection performance in patients with generalized anxiety disorder and treatment-resistant depression. Int. J. Med. Sci. 7, 224-231. doi: 10.7150/ijms.7.224

Winnicott, D. W. (1960). The theory of the parent-infant relationship. Int. J. Psychoanal. 41, 585-595.

Yiend, J. (2010). The effects of emotion on attention: a review of attentional processing of emotional information. Cognit. Emot. 24, 3-47. doi: $10.1080 / 02699930903205698$

Conflict of Interest: The authors declare that the research was conducted in the absence of any commercial or financial relationships that could be construed as a potential conflict of interest.

Copyright (C) 2019 Biran, Tripto and Arbel. This is an open-access article distributed under the terms of the Creative Commons Attribution License (CC BY). The use, distribution or reproduction in other forums is permitted, provided the original author(s) and the copyright owner(s) are credited and that the original publication in this journal is cited, in accordance with accepted academic practice. No use, distribution or reproduction is permitted which does not comply with these terms. 